\title{
Effect of Aging on Postural tachycardial index in healthy Subjects
}

\section{K. Pujitha ${ }^{* 1}$, Arpana Bhide ${ }^{2}$.}

${ }^{* 1}$ Tutor, Department of Physiology, SVIMS, SPMCW, Tirupati, Andhra Pradesh, India.

${ }^{2}$ Associate Professor, Department of Physiology, SVIMS, SPMCW, Tirupati, Andhra Pradesh, India.

\section{ABSTRACT}

Introduction: The change in parasympathetic function is generally known physiological changes in aging of man. The present study was intended to evaluate Postural tachycardial index with age.

Aim: To measure basal parasympathetic activity by using Postural tachycardial index in younger and elderly and to observe effect of aging on it.

Materials and Methods: The subjects selected are 120 in number with age group 35 to $>65$ years of both sex and they are categorized into 4 groups based on their age. Group- I: The age of 35-45 years; Group-II: The age of 45- 55 years; Group-III: The age of 55-65 Years; Group-IV: The age of $>65$ years. PTI was measured by using ECG machine.

Results: The examination of parameters body mass index, Heart Rate during resting, immediate standing were estimated for all subjects. The data was analyzed by using descriptive and inferential statistics.

Discussion: The findings suggested that the mean of PTI decreases statistically in group III and IV.

Conclusion: This study concluded that due to autonomic dysfunction the PTI decreases with increase in age.

KEY WORDS: Postural tachycardial index, Body mass index, heart rate, Autonomic dysfunction.

Address for correspondence: K. Pujitha, Tutor, Department of Physiology, SVIMS, SPMCW, Tirupati, Andhra Pradesh, India. E-Mail: k.pujithayadav@gmail.com

\begin{tabular}{|c|c|c|c|}
\hline Access this Article online & \multicolumn{3}{|c|}{ Journal Information } \\
\hline \multirow[t]{3}{*}{ Quick Response code } & \multicolumn{3}{|c|}{$\begin{array}{l}\text { International Journal of Physiotherapy and Research } \\
\text { ISSN (E) 2321-1822 | ISSN (P) 2321-8975 } \\
\text { https://www.ijmhr.org/ijpr.html } \\
\text { DOI-Prefix: https://dx.doi.org/10.16965/ijpr }\end{array}$} \\
\hline & \multicolumn{3}{|c|}{ Article Information } \\
\hline & $\begin{array}{l}\text { Received: } 13 \text { Jan } 2021 \\
\text { Peer Review: } 13 \text { Jan } 2021\end{array}$ & $\begin{array}{l}\text { Accepted: } 02 \text { Feb } \\
\text { Published (0): } 11\end{array}$ & r 2021 \\
\hline DOI: 10.16965/ijpr.2021.104 & Revised: 20 Jan 2021 & Published (P): 11 & \\
\hline
\end{tabular}

\section{INTRODUCTION}

Aging is a natural process of merely growing order in a temporal sense and should be welcomed. The different theories can be combined into two groups, according to the first group, aging is the cumulative result of random cell damage which goes throughout life, while the other group considers aging is an inevitable result of our genetic programming [1].

Most organs of the body receive dual innervations from the ANS. Eg.: Heart, Endocrine glands, and smooth muscles in the walls of hollow viscera. Some of the organs are innervated by only one division of the ANS. Eg.: Uterus, Adrenal medulla and most arterioles are innervated by sympathetic division. Glands of the stomach and pancreas are innervated by parasympathetic division only [2]. The effects of Parasympathetic stimulation are usually short lived as Acetyl choline is degraded rapidly, whereas the effects of sympathetic stimulation are wide spread and long lasting. The Hypothalamus controls and integrates the functions of both the divisions of Autonomic nervous system. 
During emotional states, limbic cortex controls the Autonomic nervous system [3]. The decline in various functions continues slowly and eventually become considerable and functionally significant as age advances. Thus physiologically, aging refers to an impaired ability to maintain homeostasis in the face of external and/or internal challenges or stresses. As a result an individual becomes more vulnerable to these challenges and stresses and may finally succumb to one of these [4]. Both parasympathetic and sympathetic nervous system which constitute the autonomic nervous system(ANS) are affected by aging. A number of tests to assess the functional status of ANS. The parasympathetic nervous system tests include beat to beat variation [5], Valsalva ratio [6] and the baroreceptor reflex sensitivity [7] and sympathetic nervous system tests include the hand grip test(8), the galvanic skin resistance [9] and the cold pressor response [10].

Thus the present study was intended to evaluate Postural tachycardial index with age which assess parasympathetic function.

\section{MATERIALS AND METHODS}

Selection of Groups: The subjects selected are 120 in number with age group 35 to $>65$ years of both sex and they are categorized into four groups based on their age.

Group- I: Subjects of 35-45 years,

Group-II: Subjects of 45-55 years,

Group-III: Subjects of 55-65 years,

Group-IV: subjects of $>65$ years.

Inclusion criteria: The study includes healthy subjects, subjects of mixed socioeconomic status.
Exclusion criteria: Subjects with diabetes mellitus, hypertension, any other debillating illness, cardio-respiratory diseases and other diseases, Subjects with obesity were excluded, Subjects with smoking and alcoholism, Subjects who are on medication were excluded, who unable to stand were excluded. The participants were carried out the physical examinations including measurement of height and weight, and body mass index (BMI). BMI was calculated as weight (in kilograms) divided by height (in squaremeters) (Quetelet's index) [11]. The test was performed between 7.30 AM and 9.00 AM before breakfast. Questionnaires evaluated about smoking habits, medication use and history of past illness. ECG machine is used to measure heart rate by calculation of R-R interval. It is recorded by using $L$ II lead. Normal HR is calculated by the $R-R$ interval at a paper speed of $25 \mathrm{~mm} / \mathrm{sec}$. As per speed of the paper, one minute is equals to1500 small squares. So, the number of cycles that could be inscribed with in this length of paper will be the heart rate.(Heart rate $=1500 /$ number of small squares in one RR interval) [12].

Heart rate response to standing (postural tachycardial index (PTI): The subject was asked to rest in a supine position for atleast $2 \mathrm{~min}$ and to stand unaided and remain standing for about a minute while ECG was being recorded continuously.

$\mathrm{PTI}=\mathrm{RR}$ interval at $30^{\text {th }}$ beat/RR interval at $15^{\text {th }}$ beat

A ratio of 1.00 or less was defined as an abnormal response.1.01-1.03 as borderline and 1.04 as normal response [13].

\section{RESULTS}

Table 1: Mean \pm SD of Age among Group I,Group II, Group III \& Group IV.

\begin{tabular}{|c|c|c|c|c|c|c|c|c|c|c|c|c|}
\hline \multirow{2}{*}{ Parameter } & \multicolumn{2}{|c|}{ Group-1(n=30) } & \multicolumn{2}{|c|}{ Group-1(n=30) } & \multicolumn{2}{|c|}{ Group-1(n=30) } & \multicolumn{2}{|c|}{ Group-1(n=30) } & \multirow{2}{*}{$\begin{array}{c}\text { GI-GII } \\
\text { 'p' value }\end{array}$} & \multirow{2}{*}{$\frac{\text { GII-III }}{\text { ' } p \text { ' value }}$} & \multirow{2}{*}{$\begin{array}{c}\text { GIII-IV } \\
\text { 'p' value }\end{array}$} & \multirow{2}{*}{$\begin{array}{c}\text { GI-IV } \\
\text { ‘p’ value }\end{array}$} \\
\hline & Mean & \pm SD & Mean & $\pm S D$ & Mean & \pm SD & Mean & \pm SD & & & & \\
\hline Age (yrs) & 40.06 & 3.03 & 50.7 & 2.98 & 60.8 & 2.68 & 73.46 & 5.18 & 0 & 0 & 0 & 0 \\
\hline
\end{tabular}

It indicates mean and standard deviation and P values of the group I,II,III \& IV. The age among all groups are found to be statistically significant

Table 2: Mean and SD of BMI in Group I, Group II, Group III \& Group IV.

\begin{tabular}{|c|c|c|c|c|c|c|c|c|c|c|c|c|}
\hline \multirow{2}{*}{ Parameter } & \multicolumn{2}{|c|}{ Group-1(n=30) } & \multicolumn{2}{|c|}{ Group-1(n=30) } & \multicolumn{2}{|c|}{ Group-1(n=30) } & \multicolumn{2}{|c|}{ Group-1(n=30) } & \multirow{2}{*}{$\begin{array}{c}\text { GI-GII } \\
\text { 'p' value }\end{array}$} & \multirow{2}{*}{$\begin{array}{c}\text { GII-III } \\
\text { 'p' value }\end{array}$} & \multirow{2}{*}{$\begin{array}{l}\text { GIII-IV } \\
\text { 'p' value }\end{array}$} & \multirow{2}{*}{$\begin{array}{c}\text { GI-IV } \\
\text { 'p' value }\end{array}$} \\
\hline & Mean & $\pm S D$ & Mean & $\pm S D$ & Mean & $\pm S D$ & Mean & $\pm S D$ & & & & \\
\hline BMI (kg/m2) & 23.59 & 1.77 & 23.44 & 2.85 & 23.31 & 2.65 & 22.9 & 1.69 & 0.13 & 0.35 & 0.21 & 0.09 \\
\hline
\end{tabular}

It indicates the mean BMI,SD and P values of Group I,II,III \& IV. There is no statistical difference 
among all the age groups but a slight decrease in Group-IV when compared with Group-I

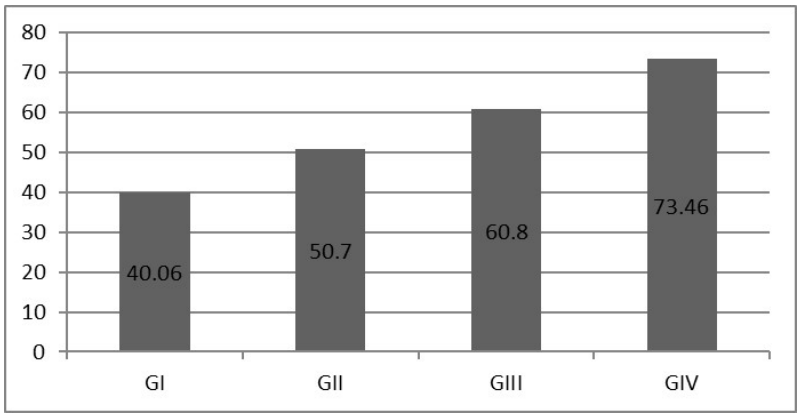

Figure 1: Age mean.



Fig. 2: BMI MEAN

Table 3: Mean and SD of PTI in Group I,Group II, Group III \& Group IV.

\begin{tabular}{|c|c|c|c|c|c|c|c|c|c|c|c|c|}
\hline \multirow{2}{*}{ Parameter } & \multicolumn{2}{|c|}{ Group-1(n=30) } & \multicolumn{2}{|c|}{ Group-1 $(n=30)$} & \multicolumn{2}{|c|}{ Group-1 $(n=30)$} & \multicolumn{2}{|c|}{ Group-1(n=30) } & \multirow{2}{*}{$\frac{\text { GI-GII }}{\text { 'p' value }}$} & \multirow{2}{*}{$\begin{array}{c}\text { GII-III } \\
p \text { ' value }\end{array}$} & \multirow{2}{*}{$\begin{array}{c}\text { GIII-IV } \\
\text { 'p' value }\end{array}$} & \multirow{2}{*}{$\begin{array}{c}\text { GI-IV } \\
\text { 'p' value }\end{array}$} \\
\hline & Mean & $\pm S D$ & Mean & $\pm S D$ & Mean & $\pm S D$ & Mean & $\pm S D$ & & & & \\
\hline PTI & 1.03 & 0.01 & 1.03 & 0.01 & 1.01 & 0.008 & 0.98 & 0.03 & 0.15 & 0 & 0 & 0 \\
\hline
\end{tabular}

Table 3 shows mean and SD of PTI in all groups. This value gradually decrease with increase in age.PTI decrease significantly in Group III \& IV. The P value is statistically highly significant.

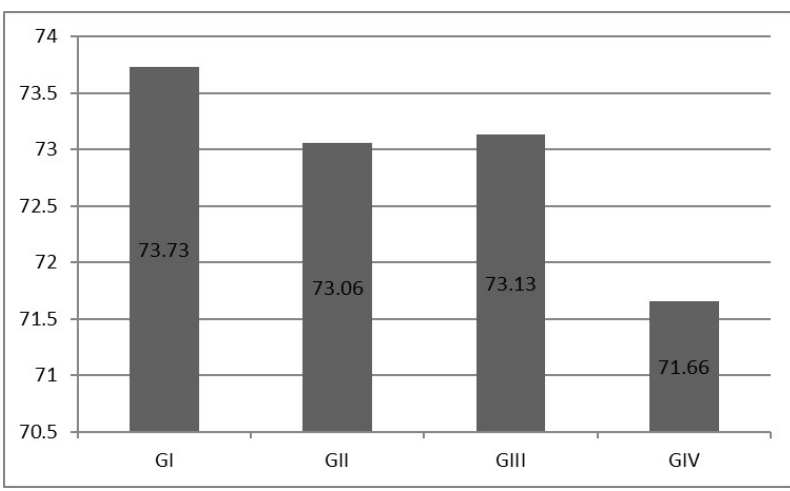

Fig. 3: Resting HR Mean.

\section{DISCUSSION}

BMI has no significant variation among all the age groups (table 1 ) but a slight decrease in Group-IV when compared with Group-I. Body composition $(\mathrm{BC})$ is relatively stable in good health conditions (Forbes GB et.al.). There are studies (Fukagawa NK et.al., Nassis GP et.al.,) that have reported a stable free fatty mass (FFM) until 60-70 years of age in men and women after which only a decline was seen in male subjects. On the contrary, some studies (Fukagawa NK) have shown loss of FFM after 40 years of age while a few others have reported peaking of FFM between 35 and 45 years. Such variations in Body Composition changes and peaking time points may be explained on the basis of differences in ethnicity, method of Body composition determination, diet and life style, socioeconomic conditions and so on [14].

Figure 4 shows variation in resting heart rate

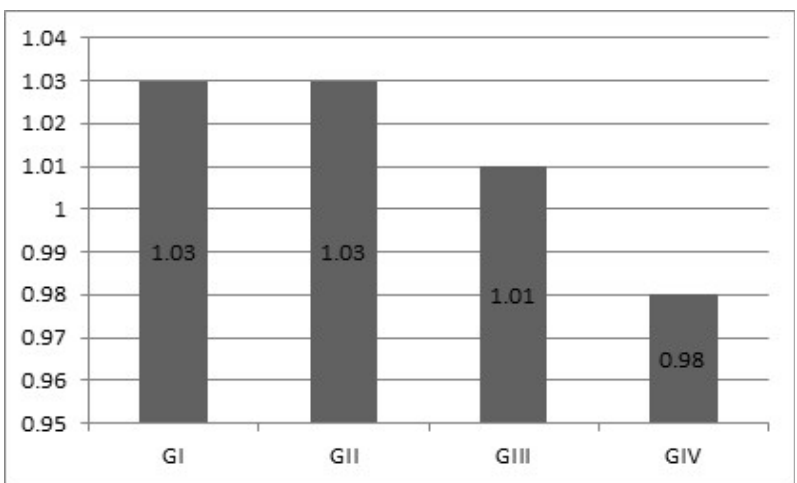

Fig. 4: PTI MEAN

among 4 groups. A slight decrease in heart rate was observed but it is not statistically significant.

Table 3 shows mean and SD of all groups.This value gradually decreases with increase in age. The variance of PTI between Group I and II are less and not significant.PTI decreases significantly in group III and IV. For this the P value is highly significant. In elderly the immediate postural reflexes are controlled neurally by sympathetic and parasympathetic nerves. Since the parasympathetic nervous system is more prone to the effect of aging than sympathetic, it is likely that the transient dysregulation of postural reflexes in older subjects is due to decrease in parasympathetic activity [15].

This study is in conformity with earlier studies done by G.Vita,J. [16] Gert Van Dijk [17], S J Piha and C Neumann [18]. This study differs from study of Ewing D J et.al., who 
initially promoted PTI as an age-independent test of parasympathetic function, may be due to smaller sample size of older control (10 subjects) and younger age of the older group (48-67 years) [19].

When subject assumes an erect posture, from supine posture, gravity causes pooling of blood in the lower limbs. As a result venous return, cardiac output and arterial BP decreases. This leads to decreased stretch of baroreceptors, activation of vasomotor center, which leads to increased sympathetic discharge, decreased vagal tone and an instantaneous increase in HR. On standing the heart rate increases until it reaches a maximum at about the 15 th beat, after which it slows down to a stable state at about 30th beat. The ratio of R-R intervals corresponding to the 30th and 15th heart beat is called the 30:15 ratio. The 30:15 ratio is a measure of parasympathetic function. The ratio decreases with age [20].

\section{CONCLUSION}

The autonomic function tests can be used to assess the status of autonomic nervous system in the elderly, as these tests are simple, non-invasive and inexpensive. Physicians have to bear in mind the age related impairment of autonomic function while evaluating cardiovascular diseases in elderly.

In this study PTI was performed among four groups. Due to autonomic dysfunction the PTI decreases with increase in age. It is important that a diagnosis of autonomic neuropathy cannot be substantiated on the basis of results from a single test. This is one of the limitation of study. Further studies are required to confirm these findings using other autonomic function tests with a large sample size of geriatric healthy subjects.

\section{Conflicts of interest: None}

\section{REFERENCES}

[1]. Indukhurana, Geriatric physiology, Text book of medical physiology. India. Elsevier 2006; Ch 12.7 : 1280-1285.

[2]. P. Vijitha, M.V. Sailaja, N. Mallikarjuna Reddy. Study of Autonomic Function Tests in Geriatric Population. Int J Intg Med Sci 2015;2(3):79-86.

[3]. WilliamF. Ganong, The Autonomic nervous system, In: Review of Medical Physiology, 23rd ed, India: McGraw -Hill Company 2010; Ch 17: 261-271.
[4]. R.L.Bijalani, The physiology of ageing, In: Text book ofmedical physiology, 2nd ed, India: Jaypee brothers 1997; Ch 1.6: 38-42.

[5]. Hilsted J, Jensen SB. A simple test for autonomic neuropathy in juvenile diabetics. Acta Med Scand. 1979;205(5):385-7.

[6]. Levin AB. A simple test of cardiac function based upon the heart rate changes induced by the Valsalva maneuver. Am J Cardiol. 1966 Jul;18(1): 90-9.

[7]. Bennett T, Hosking DJ, Hampton JR. Baroreflex sensitivity and responses to the Valsalva manoeuvre in subjects with diabetes mellitus. J Neurol Neurosurg Psychiatry. 1976 Feb;39(2):178-83

[8]. Ewing DJ, Irving JB, Kerr F, Wildsmith JA, Clarke BF. Cardiovascular responses to sustained handgrip in normal subjects and in patients with diabetes mellitus: a test of autonomic function. Clin SciMol Med. 1974 Mar;46(3):295-306.

[9]. ME Ahmed, L Delbridge, and L PLe Quesne. The role of autonomic neuropathy in diabetic foot ulceration. Jour. Neuro. Sci. 1986:47; 203-49.

[10]. LeBlanc J, Dulac S, Côté J, Girard B. Autonomic nervous system and adaptation to cold in man. J Appl Physiol. 1975 Aug;39(2):181-6.

[11]. Madeshiya, Singh, Dwivedi, Krishna and Verma. Body Mass Index, Waist Circumference and Hip Circumference are Independent Predictors of Obesitylndian J Physiol Pharmacol 2017;61(2).

[12]. Anil baran singh mahapatra. Essentials of medical physiology. $3^{\text {rd }}$ ed. Current book Int.2014.page 237

[13]. Vinutha Shankar MS, Shivakumar Veeraiah. Age related changes in Parasympathetic control of heart. International Journal of Scientific and Research Publications 2012;2(6).

[14]. DV Muralidhara, M Ramesh Bhat, MH Naveed Ahmed;Body Composition in Subjects of Different Age and BodyMass Index; 2009 JPBS.

[15]. Michael A. Pfeifer M.D. Differential changes of Autonomic Nervous System..Function with Age in Man., The American journal of Medicine Vol 75 Aug 1983. P248- 258.

[16]. G. Vita, P. Princi, R. Calabro,A. Toscano,L. Manna,C. Messina1, Cardiovascular reflex tests: Assessment of age-adjusted normal range, J Neurol Sci. 1986 Oct;75(3):263-74.

[17]. van Dijk JG, Koenderink M, Zwinderman AH, Haan J, Kramer CG, den Heijer JC, Autonomic nervous system tests depend on resting heart rate and blood pressure, Journal of autonomic nervous system, 35 (1991) p15-24.

[18]. Piha SJ, Cardiovascular autonomic reflex tests: normal responses and age-related reference values. Clin Physiol. 1991 May;11(3):277-90.

[19]. D. J. Ewing, I. W. Campbell, A. Murray, J. M. M. Neilson and B. F. Clarke Immediate heart-rate response to standing: simple test for autonomic neuropathy in diabetes, BMJ, 1978, 1, 145-157

[20]. G.K. Pal and Pravathy Pal, Autonomic function tests, In: Text book of practical physiology, India: Orient longman, 2009; Ch 40: 296-304. 